\title{
Limitations and Applications of Parataxonomy for 罢 Management in Southwestern Amazonia
}

\author{
Christopher Baraloto, Evandro Ferreira,Cara \\ Rockwell and Francisco Walthier
}

\section{Research}

\begin{abstract}
We examined the limitations of parataxonomic inventories for developing management plans for woody plant resources in tropical rain forests of southwestern Amazonia. Using compilations of herbarium labels, forest personnel interviews and published species descriptions, we assessed the accuracy of common names as parataxonomic units (PUs).
\end{abstract}

We identified 384 common names for 310 harvested woody plant species in the Brazilian state of Acre, of which only $50 \%$ were unique to a single taxonomic species. About $10 \%$ of common names referred to more than one species, more than half of which included multiple genera. For the 106 species from the Acre sample common to the MAP region including Madre de Dios, Peru and Pando, Bolivia, we identified 198 common names. Splitting was much more frequent in this sample, with more than $80 \%$ of species having more than one common name. When the Acre sample was expanded to 131 species from the Brazilian Amazon region, including the states of Amazonas and Para, we identified 740 common names, with nearly $90 \%$ of species being represented by more than one common name.

Errors and inaccuracy of parataxonomy may contribute to market instability if product orders can not be homogenized within regional markets, and to unsustainable harvests if species are mistakenly lumped into single parataxonomic units. We discuss several programs currently being implemented by our collaborative team in the region to address this issue, including field guides based on digital photography, field courses, and workshops featuring discussions between regional inventory personnel and botanists.

\section{Introduction}

Recent studies examining the integration of local peoples and their traditional knowledge into biodiversity conservation have debated the utility of parataxonomy, or the identification of biological specimens by local personnel that have not received formal training in taxonomy and systematics (Basset et al. 2000, 2004, Janzen 1993, 2004, Krell 2004, Oliver \& Beattie 1996). Parataxonomy has been championed because of a growing recognition that descriptive taxonomy has been losing both funding and prestige in recent years, resulting in shortages of personnel and finances (Godfray 2002, Oliver \& Beattie 1996). Accordingly, much attention has focused on how and when parataxonomy should be used for global inventories of biodiversity (Raven \& Wilson 1992, Sheil 2001). Despite the common participation of parataxonomists in inventories for harvested resources, considerably less attention has been paid to the application of parataxonomy to the conservation of harvested organisms including fish and forest products (Costa-Neto 2000, Drew 2005). Janzen (2004) suggested that parataxonomy will benefit biodiversity conservation by dissuading local peoples from harvesting forest products. Yet many conservation biolo-

\section{Correspondence}

Christopher Baraloto, Department of Botany, University of Florida, P.O. Box 118526, Gainesville, FL 32611, U.S.A.

baraloto@botany.ufl.edu

Evandro Ferreira, Parque Zoobotanico, Universidade Federal do Acre, Rio Branco, Acre, BRAZIL

Cara Rockwell, School of Forest Resources and Conservation, University of Florida, Gainesville, Florida, U.S.A.

Francisco Walthier, Centro dos Trabalhadores da Amazonia, Rio Branco, Acre, BRAZIL

Ethnobotany Research \& Applications 5:077-084 (2007) 
gists recognize that emerging smallholder management systems in tropical rain forests will oblige local personnel to conduct inventories designed to harvest the organisms they census (Rockwell et al. 2006, Sheil \& Lawrence 2004).

Several authors have cautioned that the benefits of parataxonomy, such as increased efficiency and comprehensiveness of collections, may be offset by the error incurred when the information is not verified by professional taxonomists (Basset et al. 2004, Krell 2004, Oliver \& Beattie 1996). Two major criticisms have surfaced. First, some have questioned the replicability of the sorting process wherein organisms are divided into discrete groups sharing morphological features (often referred to as morphospecies or recognizable taxonomic units, RTUs; hereafter referred to as parataxonomic units, PUs, after Krell (2004)). Because much of this work is done outside of the traditional taxonomy system associated with museum collections holding type specimens or species descriptions, hypotheses of PU assignation may be erroneous and are often unable to be tested (Krell 2004). Two types of errors can occur during sorting. Frequently, subtle distinctions in morphology are overlooked, and multiple similar taxa are lumped into a single parataxonomic unit (Basset et al. 2004, Oliver \& Beattie 1993). Conversely, when large numbers of samples are encountered, or when persons with different training share work on a sample, single taxonomic species may be split into multiple PUs (Krell 2004, Oliver \& Beattie 1993).

A second criticism raised for parataxonomy is that the naming of sorted samples is not standardized as with taxonomic binomials (Krell 2004). Sorting personnel may use different naming systems because of differences in language, training and/or regional customs. Both lumping and especially splitting can result from different naming systems, the former because of the application of the same name to different species among parataxonomists of different training, and the latter because of different naming systems used for the same taxa.

The consequences of lumping and splitting for biodiversity inventories are the obvious over- or under-estimations of species counts (Basset et al. 2004, Krell 2004, Oliver \& Beattie 1993). Errors in parataxonomic inventories for harvested organisms are perhaps even more dangerous (see Table 1). When multiple species share the same common name (lumping), harvesting guidelines based on maximum sustained yield may be violated without any indication in the management plan. Furthermore, buyers may receive a different species from what they intended because their association between common name and species was not the same as the parataxonomist working with the seller. Negative consequences can also occur when more than one common name is used for the same species (splitting). A given species may be under-harvested because its true population size was underestimated, potentially limiting the market for the seller.

In this paper, we examine the limitations of parataxonomic inventories for developing management plans for woody plant resources in tropical rain forests of southwestern Amazonia. We combine data from interviews, herbarium research, and literature reviews to evaluate the consistency of parataxonomic naming by local forest inventory personnel for woody plant species in the Amazon region. We ask two general questions to address the two problems associated with forest resource inventories. First, with what frequency is more than one common name attributed to a harvested taxonomic species? Conversely, we ask how often a single common name has been associated with multiple plant taxa? We examine each of these questions at three scales: among inventory technicians within Acre, Brazil, and between regions both within parts of Brazilian Amazonia (Acre, Amazonas, Para) and between the three countries in the MAP region (Madre de Dios, Peru; Acre, Brazil; Pando, Bolivia). We discuss the implications of our findings for the development of the emerging market for community forest products in the Amazon, and we present a strategic approach being implemented in Acre to improve the current situation.

\section{Methods}

\section{An overview of parataxonomic forest inventories}

Botanical identification in many tropical forest management inventories, including those used in communities in the Amazon, generally takes place in two steps. The first step occurs in the field, during which an inventory team, including local tree spotters (mateiros) and sometimes agents from a state agency or NGO, identify, mark, measure, and map trees in a pre-defined inventory unit of tens of hectares. Species names are assigned by the mateiro as a common name, based on learned associations between a series of morphological features (bark, slash,

Table 1. Lumping and splitting errors occurring in parataxonomic inventories and their potential ecological and economic consequences for harvested species.

\begin{tabular}{|l|l|l|l|}
\hline & Definition & Ecological Consequence & Economic Consequence \\
\hline Lumping & $\begin{array}{l}>1 \text { species } \\
1 \text { common name }\end{array}$ & Overharvesting & Discrepancies with orders \\
\hline Splitting & $\begin{array}{l}1 \text { species } \\
>1 \text { common name }\end{array}$ & $\begin{array}{l}\text { Poor choice of trees to harvest } \\
\text { and to leave for seed trees }\end{array}$ & $\begin{array}{l}\text { Underharvesting; } \\
\text { Insufficient volume to fill orders }\end{array}$ \\
\hline
\end{tabular}




\section{Baraloto et al. - Limitations and Applications of Parataxonomy for Community Forest Management in Southwestern Amazonia}

odor, etc.) and associated common names of diverse origins. These names are then written on the inventory sheet by the agent or another community member. The second step in most forest inventories generally takes place in the office of a local NGO or state agency. In this step, the common names from the inventory sheets are converted to taxonomic binomials. Conversions are made based on reference with lists circulating within the agencies; to our knowledge this conversion never involves consultation with professional taxonomists.

\section{Database for harvested woody plant species}

To examine the accuracy of this method to avoid the potential negative consequences associated with parataxomonic errors (Table 1), we constructed a database for all common names associated with taxonomic species that have been collected and identified by professional taxonomists. The database was divided into three parts. Our primary region of interest was the state of Acre, Brazil, where the authors are involved with community forest management for timber and non-timber forest products. Because the market for many of these products has been extended within the immediate international region, as well as to other areas within Brazilian Amazonia, we also expanded the database to include sites from these areas.

We identified harvested woody plants as species attaining at least $5 \mathrm{~cm}$ in diameter at breast height $(\mathrm{DBH})$ that have been cited in the literature or on herbarium labels as useful for wood, seeds or fruit, bark, or exudates. We compiled common names associated with each identified species for each of the three databases using herbarium ticket labels (Parque Zoobotanico, Acre; INPA, Manaus; EMBRAPA, Belem), published flora and checklists (Acevedo 2006, Araujo \& da Silva 2000, Lorenzi 1998, Pennington et al. 2004, Ribeiro et al. 1999, Vargas et al. 2005) and interviews conducted during workshops and training courses for more than 40 local treespotters in the region. When identifications to species level were unavailable or uncertain with no vouchers (less than $10 \%$ of entries), we attributed only the genus, resulting in potentially inflated error rates. We considered each common name as a distinct parataxonomic unit, because it is treated as such for management plans that outline harvesting procedures. Spelling modifications based on phonetic interpretations or accents were eliminated, potentially resulting in underestimates of actual error rates in forest management plans. All database files are available from the corresponding author upon request.

\section{Analyses}

We identified lumping errors as cases where a single common name was applied to more than one taxonomic species. We identified splitting errors as cases where more than one common name was applied to the same taxonomic species. In addition to simple cases of lump- ing and splitting such as those reported in other studies of parataxonomist error rates (Basset et al. 2000, Krell 2004, Oliver \& Beattie 1993), we also found a considerable number of cases where both lumping and splitting occurred. That is, a common name was applied to multiple species, at least one of which had at least one other common name.

Two assays have been proposed to assess the error associated with parataxonomic inventories. Oliver and Beattie (1993) calculated an error rate as the difference between the number of species and number of parataxonomic units, standardized by the number of species in the sample. Krell (2004) points out that this index can be misleading because lumping and splitting errors compensate in this calculation. He suggests the use of the accuracy rate, which is simply the proportion of cases where a PU is unique to a single taxonomic species.

For inventories of harvested species, we highlight what we believe is the most telling statistic to assess errors of species identification, the frequency of lumping, because of its potential for negative ecological and economic consequences (Table 1). We further analyze the taxonomic levels at which lumping errors occur to prioritize species complexes requiring immediate attention.

\section{Results}

\section{Lumping and splitting at different regional scales}

We identified 384 common names for 310 harvested woody plant species in the Brazilian state of Acre, of which only $50 \%$ were unique to a single taxonomic species. Almost half $(43 \%)$ of common names shared another common name for the species with which they were associated, and $11 \%$ represented more than one species (Fig. 1). For the 106 species from the Acre sample common to the MAP region including Madre de Dios, Peru and Pando, Bolivia, we identified 198 common names. Splitting was much more frequent in this sample, with more than $80 \%$ of species having more than one common name. Lumping was consistent with the Acre sample, with nearly $11 \%$ of common names representing more than one species.

When the Acre sample was expanded to 131 species from the Brazilian Amazon region, including the states of Amazonas and Para, we identified 740 common names, with more than $90 \%$ of species being represented by more than one common name.

\section{Taxonomic levels of lumping}

Overall, about half of lumping cases involved multiple species from the same genus (Table 2). In the Acre sample, more than $10 \%$ of common names referred to more than one species, more than half of which included multiple genera. Genus and family-level lumping rates were similar 

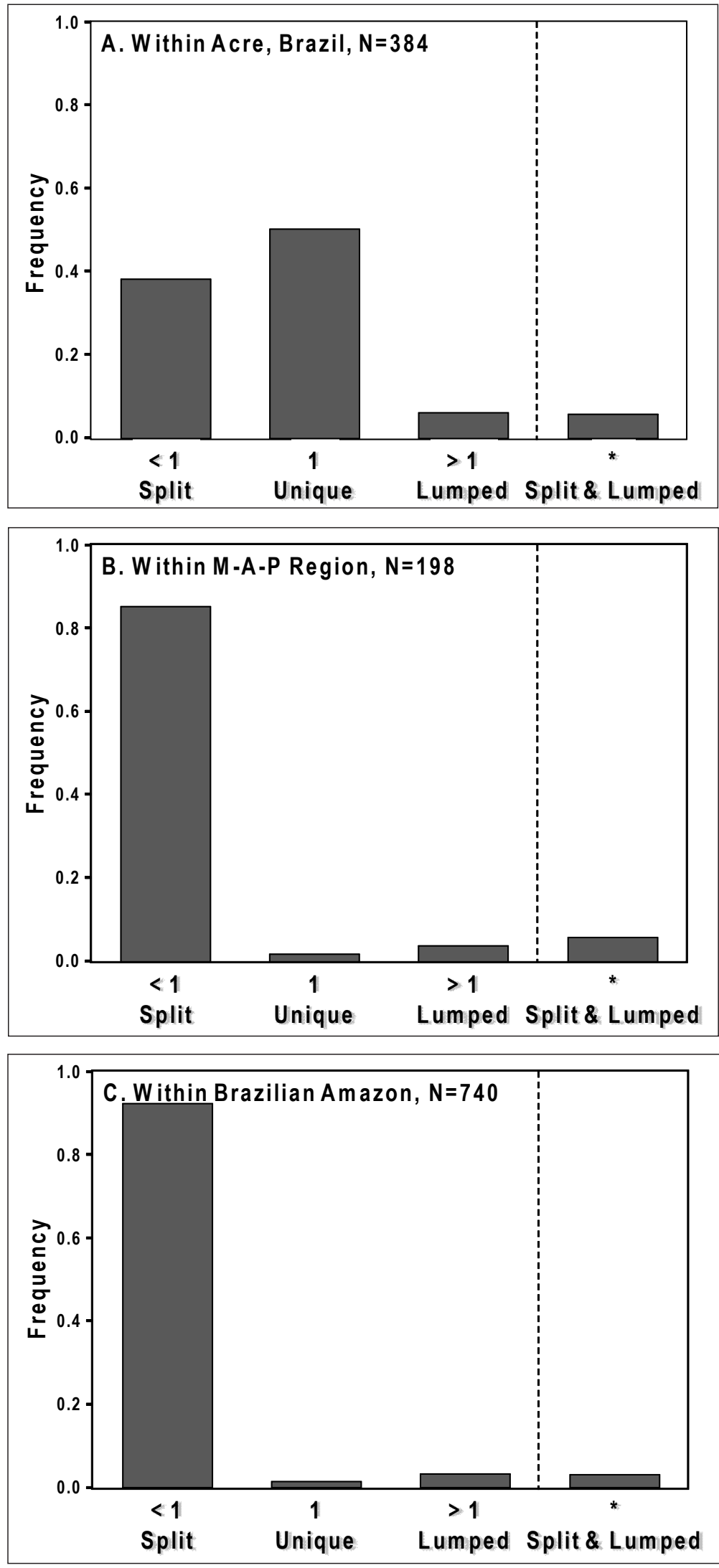

Figure 1. The frequency of errors of parataxonomic assignments of common names to taxonomic species of woody plants inventoried for community forest management in Amazonia. Each plot shows the percentage of cases where species are split among common names (ratio < 1), names are unique and correct (ratio $=1$ ), species are lumped for a single common name (ratio $>1$ ), or where a common name was applied to multiple species - at least one of which had at least one other common name $\left.{ }^{*}\right)$. Plots include databases compiled for sites within (A) eastern Acre, Brazil; (B) Acre and Madre de Dios, Peru and Pando, Bolivia (MAP); and (C) Acre and Amazonas and Para states (Brazilian Amazon). Sample sizes refer to the number of common names analyzed in each dataset. Species counts are reported in Table 3.

in the Brazilian Amazon sample, but within the international MAP region most grouped species from the same genus. About one in ten cases of lumping involved species from more than one family, and this result was consistent across the three data samples.

Accuracy and error of common names as Parataxonomic Units

We found considerable differences among the three indices we used to assess parataxonomic sorting errors, despite the relative consistency of each of these indices among the three sampled databases. As Krell (2004) suggested, the error rate was not at all consistent with the accuracy index (Table 3). In the regional samples where splitting was common, the error rate suggested by Oliver and Beattie (1993) may represent overestimates. For example, if 30 species are lumped into $15 \mathrm{PUs}$ the error is $50 \%$ according to the formula, whereas if 100 species are lumped into $1 \mathrm{PU}$, the error rate is only $99 \%$, i.e. lower than splitting 15 species into 30 PUs. For the same reason, however, the accuracy index may also over-state the problem, although to a lesser extent. The lumping frequency in all of our samples was relatively consistent at about 10\% (Table 2).

\section{Discussion}

The state of Acre in Brazil has become a global model for community forest management, in which local community members in 


\section{Baraloto et al. - Limitations and Applications of Parataxonomy for Community Forest Management in Southwestern Amazonia}

Table 2. Taxonomic levels at which taxonomic species have been lumped into the same common name class. Data are the frequency of sampled common names $(\mathrm{N})$ corresponding to each taxonomic level. Columns indicate samples from Acre, Brazil alone; Acre and Madre de Dios, Peru and Pando, Bolivia (M-A-P); and Acre and Amazonas and Para states (Brazilian Amazon).

\begin{tabular}{|l|c|c|c|}
\hline \multirow{2}{*}{$\begin{array}{l}\text { Taxonomic } \\
\text { Level }\end{array}$} & Acre & M-A-P & Brazilian Amazon \\
\cline { 2 - 4 } & 380 & 198 & 740 \\
\hline Number of common names & 190 & 4 & 11 \\
\hline 1 species & 19 & 14 & 11 \\
\hline$>1$ species, 1 genus & 22 & 4 & 10 \\
\hline$>1$ genus, 1 family & 4 & 2 & 4 \\
\hline$>1$ family & & 4 & \\
\hline
\end{tabular}

extractive reserves or colonial settlements design and implement forest management plans that maintain forest cover while harvesting forest resources (Kainer et al. 2003). An oft-overlooked yet integral component in the management of tropical forests by local peoples is the proper botanical identification of plants from which resources such as timber or non-timber products are harvested. Our study underlines the prevalence of mistakes in botanical identification that may be common in Amazonian forest inventories; a recent study in the Tapajos region found that more than half of the species identification submitted in the management plan for commercial timber harvests were errors based on association of PUs (Lacerda 2005). Our results are very consistent with this finding, if one considers that in the cases of splitting the probability of correct identification can be estimated by the ratio of species to common names, the mean of which was between 0.3 and 0.5 across the three samples. Below we discuss the scale of the problem of using common names as PUs in forest inventories at different regional scales. We then describe several programs currently being implemented by our collaborative team in Acre to address this issue.

\section{Scale of the problem}

Mistaken associations between common names and biological species can occur during the field identification (sorting) or data entry (naming) processes. In the field, two types of problems can arise. First, the mateiros sometimes simply make mistakes identifying a tree due to oftshared characteristics among species. Our observations suggest that this problem is the least frequent, although we have not quantified this frequency. A second problem occurring in the field results from parataxonomists using different common names when identifying the same species. In most cases, these multiple names are synonyms for the same species, resulting in splitting. In some cases, however, the same name is used by another mateiro to identify a different species, resulting in lumping.

In our opinion, a graver mistake is being made during the conversion of these common names to scientific names. Conversions may be erroneous for one of at least two reasons, both of which are related to the different use of common names among mateiros who have immigrated from, or have been trained in, different regions of Brazil (Schmink \& Cordero 1992). First, many of these lists are made based on common names indicated by one or several mateiros (who work together frequently) and scientific names from subsequent identification of a collected sample. Although these lists do provide one set of correspondences between common and scientific names, they are unfortunately far from complete. During our study we encountered mateiros using the same names to indicate completely different species (often multiple genera and sometimes multiple families). In other cases, names were

Table 3. Error rate and accuracy of common names as parataxonomic units representing taxonomic species of woody plants in Amazonia. Shown are the number of species and common names, and the corresponding error and accuracy estimates, for each of three samples: Acre, Brazil alone; Acre and Madre de Dios, Peru and Pando, Bolivia (MAP); and Acre and Amazonas and Para states (Brazilian Amazon).

\begin{tabular}{|l|c|c|c|c|c|}
\hline Sample & $\begin{array}{c}\text { Number of } \\
\text { Species }\end{array}$ & $\begin{array}{c}\text { Number of } \\
\text { Common Names }\end{array}$ & \% Error & \% Accuracy & \% Lumped $^{\mathbf{3}}$ \\
\hline Acre & 310 & 384 & 23.9 & 50.0 & 11.6 \\
\hline MAP & 106 & 198 & 86.7 & 2.1 & 10.3 \\
\hline Brazilian Amazon & 131 & 740 & 465 & 1.5 & 7.0 \\
\hline
\end{tabular}

1. Calculated after Oliver \& Beattie (1993), as \% Error = (Number of Species - Number of Common Names)/Number of Species.

2. Calculated after Krell (2004) as the number of cases where a common name was unique to a single taxonomic species.

3. Includes all cases where a common name represents more than one taxonomic species. 
used that were unreported in any previously published study; we have observed tens of common names used by community mateiros for which no reference from the region includes a record. A compounding observed factor stems from an understandably strong desire among forestry agents to use a complete species name in their management plans. As a result, they may search any source to obtain any scientific name for which they find a reference to an observed common name.

The regional comparisons underline a need for open lines of communication to reduce the frequency of splitting. Clearly, regional patterns of common names exist that are related to local dialects and the importance of characters (Kakudidi 2004). We present the present coarse analysis regrouping multiple samples in a region to underline the need for immediate coordinated action to address this issue. We suggest that state and federal government agencies and/or NGOs should create and distribute a list of accepted common names and their associations with biological species for use in all forest management inventories. Working with local taxonomists and parataxonomists, the key features of these complexes can be established to improve the accuracy of these associations and to develop materials for training of future taxonomists.

\section{Collaborative initiatives in the region}

Our observations have led to a list of needs both within local communities and the agencies (governmental, nongovernmental and university) aiming to serve them.

- Work with community mateiros to homogenize names. The most important need we have identified is to homogenize the use of common names such that one common name is consistently used for each species, both within and among communities, states and nations.

- Train more mateiros in the communities. A related need is the training of more mateiros in many communities. In some cases, communities are hiring external specialists to conduct their forest inventories. In other communities, only one often older man is recognized as a knowledgeable mateiro. We have witnessed a strong interest and motivation among younger community members, both male and female, to learn botany and inventory techniques. We also note that trained parataxonomists can find wellpaid periodic employment as the local forest resource markets develop, to supplement family incomes.

- $\quad$ Get one homogenized list to all agencies working with conversion of inventory data. Homogenization of names during the field component of forest inventories will be meaningless if not accompanied by concurrent efforts in the office activities during which forest management plans are written. An integral component will be the production and distribution of an updated list of correspondence that includes plurality of common names. This list should be elaborated by a team including taxonomists and experienced mateiros.

- Train agents in government and NGO agencies to use this list and to work with mateiros to homogenize names. As noted above, trained mateiros will need to work with agents trained to understand the pitfalls of identification and their potential ecological and economic consequences.

- Get referenced material to local university herbaria and to specialists to verify these names. Essential to the entire process will be the development of a researchoriented support network based in the regional herbaria (see Stern \& Eriksson 1996). Available voucher material will be vital because many of the commercial taxa are from difficult species complexes (e.g., Table 4 ) that may include new species and for which names are likely to change in the near future.

\section{Products addressing needs}

Several excellent guides have been developed for tree identification in the Amazon region, including the flora of the Ducke reserve (Ribeiro et al. 1999), a guide to the trees of Peru (Pennington et al. 2005) and the dendrological guides of the Dendrogene project of EMBRAPA in the Brazilian state of Pará. In addition, the checklist of the Flora of Acre prepared by collaborators from UFAC and the New York Botanic Garden, will be published in early 2007.

To complement these resources, we have developed a series of botanical guides catered to mateiros and agency agents that we hope will eventually address all five of the identified needs. The first guide was designed as part of the Rapid Color Guide series produced by Robin Foster and his colleagues at the Field Museum of Chicago, with support from the Gordon and Betty Moore Foundation. This guide is being designed principally for field use by sometimes analphabetic mateiros. Each plastified sheet contains photos of trunk, slash, leaf and fruits for each of six species, along with a list of common names and the appropriate scientific name and family. The trial version was

Table 4. List of prioritized commercial tree species complexes for further botanical study in Acre, Brazil..

\begin{tabular}{|l|l|l|}
\hline Common Name(s) & Genus & Family \\
\hline Abiu/maparajuba & multiple & Sapotaceae \\
\hline Angelim & multiple & Fabaceae \\
\hline $\begin{array}{l}\text { Catuaba/Cedrinho/ } \\
\text { Guaruba }\end{array}$ & multiple & Vochysiaceae \\
\hline Copaiba & Copaifera & Fabaceae \\
\hline Cumarú (ferro) & Dipteryx & Fabaceae \\
\hline Jutaí & Hymenaea & Fabaceae \\
\hline Maçaranduba & Manilkara & Sapotaceae \\
\hline Sucupira & multiple & Fabaceae \\
\hline Tauari/Corrimboque & multiple & Lecythidaceae \\
\hline
\end{tabular}




\section{Baraloto et al. - Limitations and Applications of Parataxonomy for Community Forest Management in Southwestern Amazonia}

published in June 2005 and was used in training workshops in July and August 2005. Subsequent revisions include changes suggested by participants during workshops and courses. The guide can be downloaded in pdf format free of charge from the internet at www.fmnh.org/ plantguides.

A second series of species sheets was developed by Dr. Ferreira as part of courses he taught for mateiros in the three-state MAP region in 2004. These guides are currently being updated by our group to serve as comprehensive information for all persons working with forest management in the region, and will comprise two-sided plastified sheets for each of 30 woody species including ten palms. The front side will have photos of many characteristics, including seedlings; the flip side will include a botanical description of the species and a dichotomous key that illustrates features distinguishing the species from those with similar morphology.

To address the second two needs, our collaborative group including the Acrean NGO Centro dos Trabalhadores da Amazonia (CTA) and the regional federal university (UFAC) has begun to develop an updated list of correspondence between common and scientific names, based on the Acre database reported here, that incorporates the taxonomic level of certainty due to different common name use among interviewed mateiros. The current list includes more than three hundred common names that have been used during forest inventories in the Acre communities of Porto Dias and São Luis do Remanso. The list has been developed as a Microsoft Excel file that includes a linking macro for the forest inventory sheets used by technicians in the region.

\section{Activities addressing needs}

To address the first two needs, we have been conducting botany workshops in 2004 and 2005 within two of the communities, and we participated in a module organized by CTA for the training of community forest agents. Overall, these workshops have included 55 participants from ten communities in eastern Acre, with 30 participants less than 25 years old, and 14 women. Each workshop included a series of discussions about pertinent botanical characteristics, presentations about taxonomy and the importance of names, and field discussions about links between names and characteristics using actual trees. We have also held a series of small inventory data training sessions for the forest agents working with inventory data to discuss techniques and strategies for the collection, conversion and analysis of data. These sessions included training in Microsoft Excel to use the macro functions linking the forest inventory data files to the updated correspondence list file.

To address the final need of botanical reference vouchers, we have been working to help organize and inventory the collections of commercial species within the regional herbarium in Acre. This work has uncovered a surpris- ing under-representation of samples for some of the difficult complexes of commercially-important species, leading to a prioritization list for future collections (Table 4). It is our hope that these collections will be made as part of field and herbarium training workshops with developing parataxonomists and local forestry agents. We believe these workshops will foster bi-directional exchanges wherein traditional ecological knowledge held by local mateiros regarding characters informing folk taxonomy may prove taxonomically informative (Kakudidi 2004, Sheil \& Lawrence 2004). In this way parataxonomists could complement the work of professional taxonomists and molecular biologists to resolve the true taxonomy of these difficult genera.

\section{Acknowledgements}

Support for this work was provided by the NSF-IGERT program Working Forest in the Tropics at the University of Florida, US-AID grant to the Tropical Conservation and Development program and the School of Forest Resources and Conservation at UF, the Moore Foundation, and the Hewlett Foundation. We thank the personnel at the herbaria of the Parque Zoobotanico at the Universidade Federal do Acre, INPA-Manaus, and EMBRAPA-Belem for granting access to herbarium specimens. M. Antonio of CIFOR-Bolivia provided data and extremely useful discussions. D. Daly, R. Foster, M. Hopkins and M. Silveira provided useful input on strategies for materials and workshops. We are grateful to the Centro dos Trabalhadores da Amazonia for their facilitation and administration of training workshops. F. Putz, M. Schmink, R. Wallace and D. Zarin all provided useful comments on earlier drafts. This work is dedicated to the mateiros from the communities participating in forest management in southwestern Amazonia, particularly at São Luis do Remanso and Porto Dias.

\section{Literature Cited}

Acevedo, C.V. 2006. Dinámica de florestas submetidas a manejo na Amazonia Oriental: Experimentação e simulação. Ph.D. thesis. Universidade Federal do Paraná, Brazil.

Araujo, H.J.B. de \& da Silva, I.G. 2000. Lista de Especies Florestais do Acre: Ocorrencia com base em inventarios florestais. EMBRAPA Acre, Rio Branco, Brazil.

Basset, Y., V. Novotny, S.E. Miller \& R. Pyle. 2000. Quantifying biodiversity: Experience with parataxonomists and digital photography in Papua New Guinea and Guyana. Bioscience 50:899-908.

Basset, Y., V. Novotny, S.E. Miller, G.D. Weiblen, O. Missa \& A.J.A. Stewart. 2004. Conservation and biological monitoring of tropical forests: the role of parataxonomists. Journal of Applied Ecology 41:163-174. 
Costa-Neto, E.M. 2000. Sustainable development and traditional knowledge: a case study in a Brazilian artisanal fishermen's community. Sustainable Development 8:8995.

Drew, J.A. 2005. Use of traditional ecological knowledge in marine conservation. Conservation Biology 19:12861293.

Euler, A. 2005. A vegetation ecological study of floristic and structural composition of a tropical rainforest in Antimary State Forest, Acre, Brazil. Ph.D. thesis. Yokohama National University.

Ferreira, G.C. \& Hopkins, M.J.G. 2005. Manual de Identificacao Botanica e Anatomica - Angelim. EMBRAPAAmazonia Oriental, Belem.

Godfray, H.C.J. 2002. Challenges for taxonomy. Nature 417:17-19.

Janzen, D.H. 1992. A south-north perspective on science in the management, use, and economic development of biodiversity. Pp. 27-52 in Conservation of Biodiversity for Sustainable Development. Edited by O.T. Sandlund, K. Hindar \& A.H.D. Brown. Scandinavian Press, Oslo.

Janzen, D.H. 1993. Taxonomy: Universal and essential infrastructure for development and management of tropical wildland biodiversity. Pp. 100-113 in Proceedings of the Norway/UNEP Expert Conference on Biodiversity. Edited by O.T. Sandlund \& P.J. Schei. Directorate for Nature Management and Norwegian Institute for Nature Research, Trondheim.

Janzen, D.H. 2004. Setting up tropical biodiversity for conservation through non-damaging use: participation by parataxonomists. Journal of Applied Ecology 41:181-187.

Kakudidi, E.K. 2004. Folk plant classification by communities around Kibale National Park, Western Uganda. African Journal of Ecology 42(S1):57-63.

Kainer, K.A., M. Schmink, A.C.P. Leite \& M.J. da Fadell Silva. 2003. Experiments in forest-based development in Western Amazonia. Society and Natural Resources 16:869-886.

Krell, F.-T. 2004. Parataxonomy vs. taxonomy in biodiversity studies - pitfalls and applicability of 'morphospecies' sorting. Biodiversity and Conservation 13:795-812.

Lacerda, A.E.B. 2005. Conservation and Sustainability within Brazilian Amazon Forests: The role of botanical identification. M.S. thesis, University of Reading, U.K.

Lorenzi, H. 1998. Arvores Brasileiras. 2nd edition. Volumes 1 and 2. Editora Plantarum, Sao Paolo, Brazil.
Oliveira, L.C. 2005. Efeito da exploração da madeira e de diferentes intensidades de desbastes sobre a dinâmica da vegetação de uma área de 136ha na Floresta Nacional do Tapajós. Piracicaba. Ph.D. Thesis. Escola Superior de Agricultura "Luiz de Queiroz", Universidade de São Paulo, Brazil.

Oliver, I. \& A.J. Beattie. 1993. A possible method for the rapid assessment of biodiversity. Conservation Biology 7:562-568.

Oliver, I. \& A.J. Beattie. 1996. Designing a cost-effective invertebrate survey: A test of methods for rapid assessment of biodiversity. Ecological Applications 6:594-607.

Pennington, T.D., C. Reynel \& A. Daza. 2004. Illustrated Guide to the Trees of Peru. David Hunt, Sherbourne, UK.

Raven, P.H. \& E.O. Wilson. 1992. A fifty-year plan for biodiversity surveys. Science 258: 1099-1100.

Ribeiro, J.E.L.S., M.J.G. Hopkins, A. Vicentini, C.A. Sothers, M.A.S. Costa, J.M. de Brito, M.A.D. De Souza, L.H.P. Martins, L.G. Lohmann, P.A.C.L. Assunção, E. da C. Pereira, C.F. da Silva, M.R. Mesquita \& L.C. Procópio. 1999. Flora da Reserva Ducke: Guia de identificação das plantas vasculared de uma floresta de terra-firme na Amazônia Central. INPA-DFID, Manaus,Brazil.

Rockwell, C., K. Kainer, N. Marcondes \& C. Baraloto in press. Ecological limitations of reduced-impact logging at the smallholder scale. Forest Ecology and Management.

Schmink, M. \& M.L. Cordeiro. 1992. Urbanização na Amazônia: Mudanças econômicas e demográficas em Rio Branco, Acre, Brasil. Universidade Federal do Acre e Universidade da Florida, Rio Branco, Brazil.

Sheil, D. 2001. Conservation and biodiversity monitoring in the tropics: realities, priorities and distractions. Conservation Biology 15:1179-1182.

Sheil, D. \& A. Lawrence. 2004. Tropical biologists, local people and conservation: new opportunities for collaboration. Trends in Ecology and Evolution 19:534-638.

Stern, M.J. \& T. Eriksson. 1996. Symbioses in herbaria: Recommendations for more positive interactions between plant systematists and ecologists. Taxon 45:49-60.

Vargas, I., B. Mostacedo \& C. Jordan. 2005. Guia Illustrada de las Principales Especies Forestales de Bolivia. IBIF/WWF, Santa Cruz, Bolivia. 